\title{
Histological and Morphometrical Study of the Filiform Papillae in the Domestic Rabbit (Oryctolagus cuniculus)
}

\author{
Mircea CIPOU, Cristian MARTONOS*, Adrian Florin GAL, Vasile RUS, Ion VLASIUC, Viorel \\ MICLĂUS,, Aurel DAMIAN
}

\begin{abstract}
${ }^{1}$ Department of Fundamental and Preclinical Sciences, Faculty of Veterinary Medicine, University of Agricultural Sciences and Veterinary Medicine, Cluj-Napoca (Mănăștur Street No. 3-5, Cluj-Napoca, 400000, Romania)

*Corresponding author: Cristian Martonos e-mail: cristian.martonos@usamvcluj.ro
\end{abstract}

\section{RESEARCH ARTICLE}

\begin{abstract}
The domestic rabbit is often preferred as an experimental model in diverse research and especially those regarding pathologies of the oral cavity, both in human and veterinary medicine. From five domestic mixed breed rabbits, fragments were harvested from the three regions of the tongue: apex, body and root, for histological investigations. The samples were processed by embedding in paraffin, sectioned at a thickness of $5 \mu \mathrm{m}$ and stained with Goldner's trichrome method. The histological examination highlighted the presence of the filiform papillae on the entire dorsal surface of the tongue, with morphological particular carachteristics for each portion. The dimension of the filiform papillae of the rabbit's tongue differs both regarding the length as well as the thickness and density. The shortest filiform papillae were found on the tip of the tongue, then the length increases progressively, reaching the maximum level on the middle portion and decreases in the last portion. The density also differs, in in the three compartments examined, being the highest in the anterior part and the lowest in the posterior part. The thickness of the filiform papillae is inversely proportional to their density. The thickness of the papillae is smaller where the density is higher and highest where the density is lowest. The upper surface of the filiform papillae is variably keratinized depending on the lingual segment. The papillae with the highest level of keratinization are arranged in the body part of the tongue, and those at the tip and root are slightly lower.
\end{abstract}

Keywords: rabbit; tongue; filiform papillae.

Received: 07 November 2020 Accepted: 01 February 2021 Published: 14 May 2021

DOI:

10.15835/buasvmcn-vm:2020.0044

\section{INTRODUCTION}

The domestic rabbit is taxonomically classified in kingdom Animalia, phylum Cordata, subphylum Craniata, class Mammalia, subclass Theria, infraclass Placentalia, order Lagomorpha, family Leporidae, subfamily Leporinae, genus Oryctolagus, species Orytolagus cuniculus (Bud et al., 2011; Zhang 2011; Marcus et al., 2018).The rabbit as species is one of the most preferred for the use in biomedical research as experimental research models in human medicine and is phylogenetically closer to the human than other research species (Mapara et al., 2012). The mammalian tongue is very important in feedstuff prehension, emesis, swallowing, breathing, coughing, body cleansing and producing sounds (Iwasaki, 2002; Sokoloff and Burkholder, 2012; Stan and Martonos, 2016; Rus et al. 2019). In oral pathology affecting the tongue, the rabbit was used with success as an experimental research animal in evaluating new treatments to promote healing wounds of the tongue, developing new surgical techniques and as a model in research of the squamous cell carcinoma expanding from the tongue epithelium (Kummoona, 2010; Li et al., 2010; Yonezawa et al., 2012).In veterinary medicine, the oral pathology in rabbits is very particular being determined by morphological particularities of the oral cavity in this species (Crossley, 2003; Fahrenkrug, 2015). Oral tumors were reported to appear in rabbits as well as in other company animals (Miwa et al., 2015) and for a correct diagnosis, it's important to know the normal morphology of all the oral cavity components. Besides those mentioned, the incidence of rabbits is constantly growing 
in veterinary practices and the emotional significance determine owners to make serious investments for their pet well being.

The aim of the present study is the detailed histological and morphometrical investigation of the filiform papillae of the adult rabbit tongue as a base for future research in the domain of pathology and experimental medicine.

\section{MATERIALS AND METHODS}

The biological material used in this study was five adult domestic rabbits, 14 months old common breed. The animals came from a licensed breeder who slaughtered them for their own consumption. With this occasion, we collected fragments from the three parts of the tongue: apex, body and root, for performing histological investigations. The samples were fixed in $10 \%$ buffered formalin for five days, dehydrated with alcohol in ascending concentration (700, 960 and absolute), clarified with butyl alcohol (1-butanol) and embedded in paraffin. Longitudinal sections of $5 \mu \mathrm{m}$ thickness were obtained by a LEICA RM2125RT microtome, and stained by Goldner's trichrome method. Examination of histological preparations was performed on an Olympus BX41 microscope equipped with a digital camera (Olympus E330) for image capture. Microscopic photographs were taken from all regions of the tongue, using the same magnification to make the results comparable. The histological images obtained were processed with the Adobe Photoshop 2020 program and measurements were performed with the AmScope v4.8.15934 digital microscopy program.

\section{RESULTS AND DISCUSSIONS}

The dorsal surface of the tongue is covered by a squamous stratified epithelium that has a moderate degree of keratinization, only on the surface of the filiform papillae. Numerous papillae are present on the surface of the rabbit's tongue, of which the filiform papillae are numerically dominant.

The filiform papillae of the rabbit's tongue differ in shape, position, length, thickness, density and keratinization degree in relation to the anatomical region of the tongue.

As for shape, they are cylindrical on the entire surface of the apex of the tongue, after which they gradually become high and conical at the level of the body of the tongue, so that towards the root of the tongue to keep the conical shape, but they become progressively shorter. Both types of papillae (cylindrical and conical) have an antero-posterior curved tip, with the highest degree of curvature at the tip of the tongue, then gradually decreases so that the short conical papillae at the base of the tongue have a minimum degree of curvature.

As for the position, the cylindrical ones are arranged perpendicular to the surface of the tongue, the tall conical ones slightly inclined an anteroposterior sense, and the small conical ones prominently inclined anteroposterior.

In length, the filiform papillae differ in the three lingual segments, tip, body and base. At the level of the tip of the tongue, the average length of the filiform papillae was $554 \mu \mathrm{m}$, on the body of the tongue $650 \mu \mathrm{m}$, and on the root 532 $\mu \mathrm{m}$. By comparing them with each other, we find that those on the tip of the tongue are 1,041 times larger than those on the root, and those on the body are 1,173 times larger than those on the tip of the tongue and 1,214 times larger than those at the root of the tongue.

As for the thickness, the filiform papillae on the rabbit's tongue differ in the three lingual segments. The average thickness of the papillae was on the tip of the tongue $156 \mu \mathrm{m}$, on the body of the tongue $160 \mu \mathrm{m}$, and on the root of the tongue $202 \mu \mathrm{m}$. If we compare the thickness of the papillae in the three anatomical regions, we find that those on the body of the tongue are 1,025 times thicker than those on the tip, and those on the root 1,294 times thicker than those on the tip and 1,262 times thicker than those on the body of the tongue.

Regarding the keratinization level, there are also differences, the papillae with the highest degree of keratinization being those in the body of the tongue, while those on the tip and root of the tongue have only discrete keratinization. It should be noted that the keratinization process is more pronounced on the posterior face of the papillae than on the anterior one noticed by the cells affinity to the dye.

The results obtained in this study highlight that the filiform papillae on the rabbit's tongue are present in very large numbers on the entire dorsal surface of the organ. They are not identical on the whole surface, there are differences in length, thickness, arrangement, density, depending on the considered segment of the tongue. They have a cylindrical shape on the tip of the tongue but with differences in height, being slightly shorter towards the tip of the tongue and longer towards the body of the tongue. On the body and the root of the tongue, the filiform papillae have a conical shape, being high conical on the body of the tongue and short conical at the root. In thickness, the thinnest ones are on the tip of the tongue, and the thickest ones are on the root of the tongue. Their density is inversely proportional to the thickness, so that the most numerous are on the tip of the tongue and the least on the root.

Rodent mammals include a wide variety of species and subspecies. All rodents have lingual papillae on the dorsal surface of the tongue, but there are differences between them due to taxonomic evolution, habitats and feeding habits (Yoshimura et al., 2002; Ciena et al., 2017; Rus et al., 2019).

Studying the postnatal development of lingual papillae in rabbits, some authors have concluded that there is a direct relationship between the type of feedstuff consumed and the development of papillae. They found that the papillae complete their formation from the third to the fourth week of postnatal life when the transition is made from breastfeeding 
to food consumption with a completely different consistency (Nabil and Tawfiek, 2020). Nonaka et al., (2008) studied the lingual papillae of the rabbit tongue, especially in terms of their size and shape.

Studying the tongue in adult mice, Toprak (2006) found the presence of filiform papillae on the dorsal surface of the tongue, from the apex to the vallate papillae of the root. He found the existence of three different types of filiform papillae: cylindrical in the anterior part of the tongue, large conical on the intermolar eminence, and small conical in the posterior part of the tongue. He also founded more pronounced keratinization on the anterior surface of the papillae than on the posterior one. The author states that the situation is comparable in rats. The aspects reported by Toprak (2006) in mice and rats are similar to those observed by us in rabbits in terms of the shape and disposition of the filiform papillae (Table $1)$.

Studying guinea pig tongue papillae, some authors concluded that filiform papillae were the most numerous and presented several shapes, ranging from conical to branched, located on distinct regions of the dorsal epithelium of the tongue (Kobayashi, 1990; Ciena et al., 2017). Regarding the size of the filiform papillae on the guinea pig tongue, Ciena et al. (2017) divided them into four categories: long, short, branched, and large. Cylindrical and conical filiform papillae were also highlighted in the flying squirrel, Emura et al. (1999). Numerous randomly distributed filiform papillae have also been highlighted on the mucosa of the maned sloth with three fingers (Benetti, 2009).

The scientific literature reports, in some species of mammals, the existence of filiform papillae that have the tip divided into two branches, as is the case of the three-fingered maned sloth (Benetti, 2009), or even three branches as found by Boshell et al. (1982) in the anterior part of the cat's tongue.

Performing comparative morphological studies of the tongue in vertebrate animals, some authors have concluded that morphological and functional variations of the organ may be related to events of evolution and nutrition. Due to the very important role that the tongue plays in the prehension of food and in the process of mastication in vertebrates, it has significant morphological variations that seem to be adaptations to environmental conditions and the type of food consumed by each species (Iwasaki, 2002; Ding et al., 2016).

Table 1. Filiform papillae morphometry of the rabbit tongue

\begin{tabular}{cccc}
\hline \multirow{2}{*}{ Parameters } & \multicolumn{3}{c}{ Anatomic regions of the tongue } \\
\cline { 2 - 4 } & Apex & Body & Root \\
\hline Mean lenght & $554 \mu \mathrm{m}$ & $650 \mu \mathrm{m}$ & $532 \mu \mathrm{m}$ \\
\hline Mean thickness & 156 & 160 & 202 \\
\hline Mean density $\mathbf{2 1 0 2 5 0 0} \boldsymbol{\mu m}^{\mathbf{2}}$ & 81 & 56,25 & 36 \\
\hline
\end{tabular}

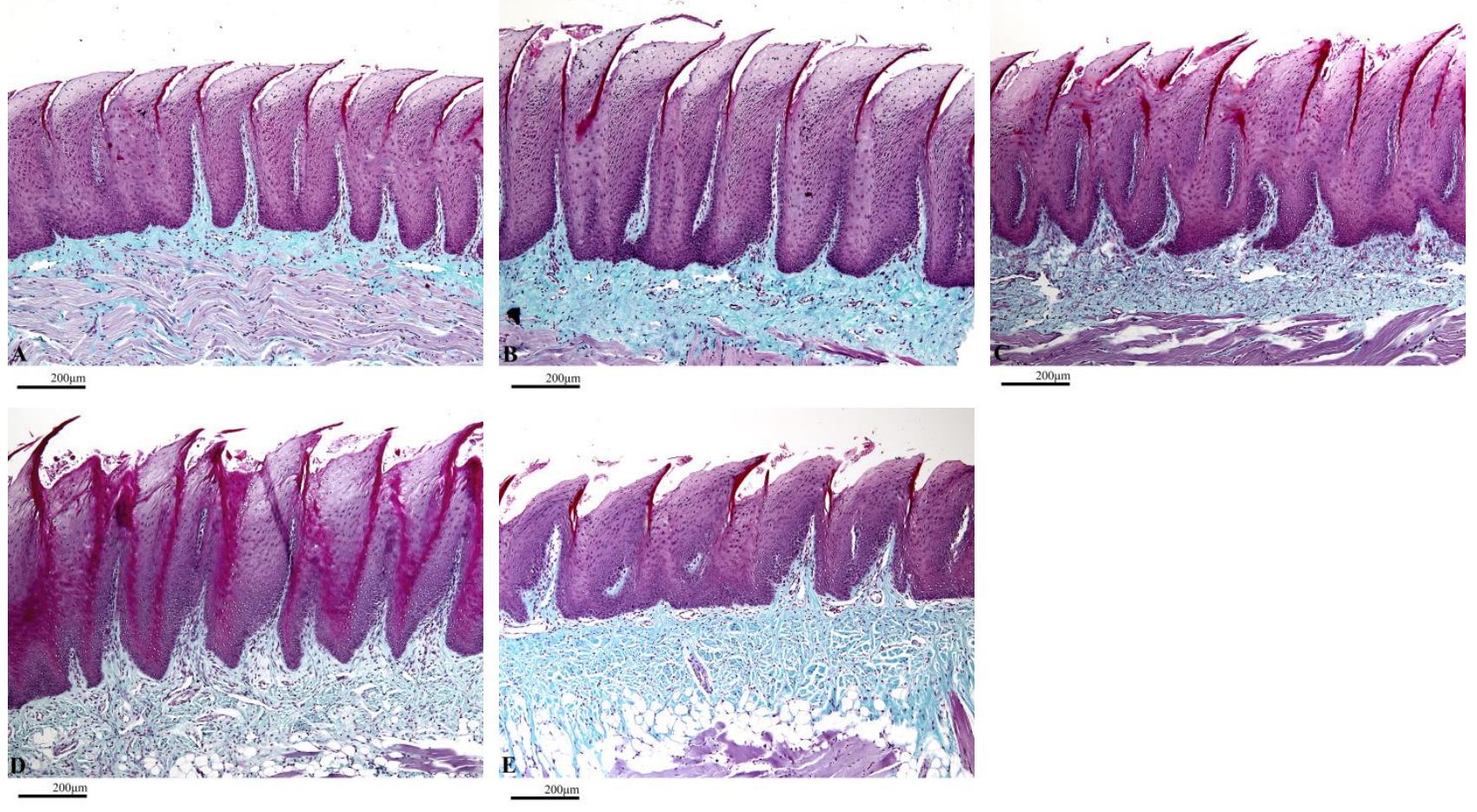

Figure 1. The aspect of the rabbit tongue filiform papillae. A: Filiform papillae on the anterior part of the apex; B: Filiform papillae of the apex closer to the junction with the tongue's body; C: Filiform papillae from the anterior part of the tongue's body; D: Filiform papillae from the posterior part of the tongue's body; E: Filiform papillae from the root of the tongue. 


\section{CONCLUSIONS}

The filiform papillae on the dorsal surface of the rabbit's tongue differ regarding the shape and size depending on the anatomical segment, being short cylindrical and high cylindrical on the apex of the tongue, high conical on the body and short conical on the root.

The thickness of the filiform papillae increases progressively in a anteroposterior sense, so that the thinnest papillae are on the tip of the tongue and the thickest on the root, and the highest density is on the tip of the tongue and the smallest on the root.

The keratinization level of the epithelium on the filiform papillae of the rabbit's tongue is different, being more pronounced in the body, while in the tip and root the keratinization processes are relatively discreet.

Author Contributions: M.C.-Organising the experiment, information research, writing the article, morphometric measurements; C.M.-Anatomic dissection, article arrangement on the magazine's requirements, sending the article and the correspondence with the editorial staff; V.R.- the sample prelevation for the histologic examination, I.V.- histological processing, morphometric measurements; V.M.-examination of the histological slides, microscopic photographing, results description; A.D.-coordination of the research team.

Funding Source: This research was funded by from the budget of the University of Agricultural Sciences and Veterinary Medicine of Cluj-Napoca doctoral school.

\section{Conflicts of Interest}

The authors declare that they do not have any conflict of interest.

\section{REFERENCES}

1. Benetti EJ, Pícoli LC, Guimarães JP, Motoyama AA, Miglino MA, Watanabe LS. Characteristics of Filiform, Fungiform and Vallate Papillae and Surface of Interface Epithelium-Connective Tissue of the Maned Sloth Tongue Mucosa (Bradypus torquatus, Iliger, 1811): Light and Scanning Electron Microscopy Study. Anatomia, Histologia, Embryologia 2009; 38(1): 42-48

2. Boshell JL, Wilborn WH, Singh BB. Filiform papillae of cat tongue. Acta Anatomica 1982; 114(2): 94-105

3. Bud I, Vlădău VV, Petrescu-Mag V. Raising rabbits,.Ceres Bucharest Publishing House, 2011.

4. Ciena AP, Dos Santos AC, Vasconcelos BG, Rici REG, De Assis Neto AC, De Almeida SRY et al. Morphological characteristics of the papillae and lingual epithelium of guinea pigs (Cavia porcellus), Acta Zoologica. 2017; Vol.100 (1), 53-60.

5. Crossley DA. Oral biology and disorders of lagomophs, Review article in The veterinary clinics Exotic Animal Practice 2003: 6(3): 629-659

6. Ding Y, Yu S, Shao B. Anatomical and histological characteristic of the tongue and tongue mucosa linguae in the cattleyak (Bos taurus $\times$ Bos grunniens). Frontiers in Biology 2016; 11(2): 141-148.

7. Emura S, Tamada A, Hayakawa D, Chen H, Jamali M, Taguchi H, Shoumura S. SEM study on the dorsal lingual surface of the flying squirrel, Petaurista leucogenys, Annals of Anatomy - Anatomischer Anzeiger 1999; 181 (5): 495-498

8. Fahrenkrug P. Foreword in: Dentistry in rabbits and rodents by Estella Böhmer, Willey Blackwell Publishing 2015.

9. Iwasaki S. Evolution of the structure and function of the vertebrate tongue. Journal of Anatomy 2002; 201(1): 1-13

10. Kobayashi K. Three-dimensional architecture of the connective tissue core of the lingual papillae in the guinea pig. Anatomy and Embryology 1990; 182(3): 205-215

11. Kummoona R. Reconstruction by Lateral Cervical Flap of Perioral and Oral Cavity. Journal of Craniofacial Surgery 2010; 21(3): 660-665.

12. Li S, Ren G, Jin W, Guo W. Establishment and characterization of a rabbit oral squamous cell carcinoma cell line as a model for in vivo studies. Oral Oncology 2011; 47(1): 39-44.

13. Mapara M, Thomas BS, Bhat KM. Rabbit as an animal model for experimental research, Dental Research Journal 2012; 9(1): 111-118

14. Marcus I, Sevastre B, Sarpataki O. Biology and pathology of the laboratory animals, Risoprint Cluj-Napoca publishing house, pg 294-295, 2018.

15. Miwa Y, Nakata M, Takimoto H, Chambers JK, Uchida K. Spontaneous oral tumours in 18 rabbits (2005-2015). Journal of Small Animal 2019: Bristish Small Animal Veterinary Association pg 1-5, Available from: https://onlinelibrary.wiley.com/doi/abs/10.1111/jsap.13082 
16. Nabil TM, Tawfiek MG. Morphological study of the rabbit gustatory lingual papillae during postnatal life by light and scanning electron microscopy, Anatomical Science International 2020; 95:455-469

17. Nonaka K, Zheng JH, Kobayashi K. Comparative morphological study on the lingual papillae and their connective tissue cores in rabbits. Okajimas Folia Anatomica Japonica, 2008; 85(2): 57-66

18. Rus V, Ghiurco F, Ihuț A, Ruxanda F, Martonos C, Miclăuș V, Gal AF. Microscopical study regarding the arrangement of tongue muscle in Chinchillas (Chinchilla lanigera), Scientific papers, Veterinary medicine, 2019; 1 (61):34-41.

19. Sokoloff A, Burkholder T. Tongue Structure and Function. In: McLoon L., Andrade F. (eds) Craniofacial Muscles. Springer, New York, NY. 2012.

20. Stan F, Martonos C. Comparative splahnology of domestic mammals, AcademicPress Cluj-Napoca 2016.

21. Toprak B. Light and scanning microscopic structure of filiform papillae in mice, VETERINARSKI ARHIV 2006; 76 (6), 555-562

22. Yonezawa H, Yamada S, Yanamoto S, Yoshitomi I, Kawasaki G, Umeda M. Effect of polyglycolic acid sheets with fibrin glue (MCFP technique) on the healing of wounds after partial resection of the border of the tongue in rabbits: a preliminary study. British Journal of Oral and Maxillofacial Surgery 2012; 50(5), 459-463

23. Yoshimura K, Shindo J, Kobayashi K. Scanning electron microscopy study of the tongue and lingual papillae of the California alien (Zalophus californianus californianus) The Anatomical Record 2002; 267(2): 146-153.

24. Zhang ZQ An outline of higher-level classification and survey of taxonomic richness Class Mammalia Linnaeus, 1758 in Zootaxa 3148 Animal biodiversity. Magnolia Press, 2011. 